\title{
KNOWLEDGE, ATTITUDE AND PERCEPTION OF A SAMPLE OF BREAST CANCER PATIENTS TOWARDS COVID-19 PANDEMIC
}

\author{
Tarek Hussien Kamel*, Nagy Samy Gobran*, Sherif Hassanien Ahmed*, \\ Abanoub Samir Karam*
}

\author{
Department of Clinical \\ Oncology and Nuclear Medicine \\ - Faculty of Medicine - Ain \\ Shams University, Cairo, Egypt. \\ Corresponding author \\ Abanoub Samir Karam Gayed \\ Mobile: (+2) 01002869267 \\ E.mail: \\ Abanoob_sk@yahoo.com
}

Received: $1 / 7 / 2021$

Accepted:25/7/2021

Online ISSN: 2735-3540

\begin{abstract}
:
Background: COVID-19 pandemic scares everybody especially cancer patients. This affects the treatment protocols for some patients

Aim of the work: To translate the questionnaire to Arabic and to validate it. Also to assess the patients' knowledge, attitude and perception about the COVID-19 pandemic and their willingness about continuation of anti-cancer treatment.

Patients \& methods: A pilot study on 50 breast cancer patients who are actively receiving chemotherapy in the department of clinical oncology, Ain Shams University were included from November $1^{\text {st }}$, 2020 to March $1^{\text {st }}$, 2021, during the COVID-19 pandemic were included to answer the questionnaire. The study correlated sociodemographic data, stage and treatment plan of the patients with their answers in the questionnaire.
\end{abstract}

Results: knowledge about COVID-19 among breast cancer patients was significantly correlated with age $<50$ years old $(P=$ 0.0293). Nearly half of patients (46\%) have good knowledge about COVID-19 regarding spread, symptoms and outcome. All of the patients wanted to continue their chemotherapy. Nearly half of our patients (48\%) had no worry about catching COVID-19. One third of the patients (32\%) were bothered about cancer progression, almost one third (28\%) were bothered about deferring chemotherapy and the other one third (28\%) nothing was bothering them. Most of the patients (72\%) knew that chemotherapy causes immunosuppression which increase the risk of complications in case of catching COVID19. Most of the patients (90\%) fear suffering from cancer progression if treatment stopped. Majority of our patients were taking personal protective measures.

Conclusion: This study shows that breast cancer patients are more worried about disease progression than COVID-19 and wish to continue chemotherapy during this pandemic.

Key words: COVID-19, Breast cancer, Questionnaire

\section{INTRODUCTION:}

COVID-19 is a novel coronavirus ${ }^{(\mathbf{1})}$ In December 2019, the infection started in Wuhan, China, since then it spread across the globe ${ }^{(2)}$. On $30^{\text {th }}$ January 2020, the World Health Organization (WHO) declared the current outbreak of COVID-19 ${ }^{(3)}$ and later on $11^{\text {th }}$ of Mar-2020 the number of cases outside China has increased and the number of affected countries has increased, that made the WHO to declare the COVID19 as a global pandemic ${ }^{(4)}$. Infection with SARS-CoV-2, in April $5^{\text {th }}$, 2021, has resulted in more than 131 million laboratory- 
confirmed cases of COVID-19 and more than 2,850,000 confirmed deaths ${ }^{(4)}$. In April $5^{\text {th }}, 2021$, there are 205,000 SARS-CoV-2 cases and 12,163 total deaths in $\operatorname{Egypt}^{(\mathbf{4})}$. The COVID-19 has brought huge impacts to all people, especially to the medical and health systems. It has also brought great challenges to the treatment of patients with cancer $^{(\mathbf{6})}$. due to the nature of the cancer disease, characteristics of cancer patient (who usually have other comorbidities) and the nature of their immuno-suppressive treatments. Patients with cancer may suffer more during this epidemic period as they are immunocompromised. So their bodies are less likely to be able to fight against the COVID-19 if they got infected ${ }^{(7)}$. The Center for Disease Control and Prevention (CDC) has published the largest case series to date of COVID-19 in mainland China and reported a case fatality rate of $5.6 \%$ among patients with cancer ${ }^{(8)}$. In a Korean study by Kim YJ, coronavirus pneumonia had a $24 \%$ mortality in cancer patients compared to $3 \%$ in non-cancer patients ${ }^{(\mathbf{9})}$. Most chemotherapeutic agents can depress the immune system which increase infection risks for cancer patients. Cyclophosphamide, cisplatin, methotrexate and taxanes are among the most potent agents that result in bone marrow suppression in the form of thrombocytopenia, neutropenia \& lymphopenia ${ }^{(10)}$. Lymphopenia can induce progression to pneumonia amongst patients with respiratory viral infection ${ }^{(11)}$. A study from India by Joydeep Ghosh showed that oncology patients are more worried about cancer progression than the COVID-19 and wish to continue chemotherapy during this pandemic ${ }^{(\mathbf{1 2})}$.

\section{PATIENTS \& METHODS:}

The study population consisted of 50 consecutive breast cancer patients who were actively receiving chemotherapy in the department of clinical oncology, Ain Shams University were included from November $1^{\text {st }}, 2020$ to March $1^{\text {st }}, 2021$, during the COVID-19 pandemic. All patients aged more than 18 years with pathologically proven breast cancer and has the ability to read, write or comprehend spoken language were included in our study. It is a pilot study in all patients who fulfilled the aforementioned criteria. The questionnaire translated to Arabic then validated. Content validity of the questionnaire confirmed by seeking the appraisal of 3 experts (Oncology Professors). The face validity ensuring that all patients are understanding the questionnaire was tested by administering the questionnaire to a group of 10 patients to ensure that all terms used were understandable and to clarify any ambiguity. The modified final questionnaire was piloted on a group of patients $(n=50)$. Because of the pandemic, a non-interventional surveybased study was done. Patients were excluded if they were unable to comprehend spoken language or were in severe physical inability to answer the questionnaire because of cancer or therapy related complications.

\section{Statistics:}

Patients' data were collected and tabulated and answers were tabulated to analyze the correlation between them. Descriptive statistics used to examine demographic characteristics and study variables. Shapiro-Wilk test used to test normal distribution of continuous variables. Chi-squared test or Fisher's exact test used for the relationship between two categorical variables.

Statistical analysis was done using MedCalc ${ }$ Statistical Software version 19.7.1 (MedCalc Software Ltd, Ostend, Belgium; https://www.medcalc.org; 2021).

\section{RESULTS:}

In the interval from November 2020 to March 2021, fifty breast cancer patients on chemotherapy were included in our study. Twenty patients aged less than fifty years 


\section{Knowledge, Attitude And Perception Of A Sample Of Breast Cancer Patients Towards Covid-19 Pandemic}

and thirty patients aged fifty years or more with median age 52 years old. Fourty nine patients were females and only one patient was male. Thirty four patients were educated, eleven patients had high education (graduated from university or institute), twenty three patients had uptohigh education (finished school or had diploma). Sixteen patients were illiterate. Thirty three patients had early breast cancer and the aim of treatment was curative. Seventeen patients were metastatic breast cancer and the aim of treatment was palliative. (Table 1)

Table (1) Patients' characteristics $(\mathrm{n}=50)$

\begin{tabular}{|l|l|l|l|}
\hline \multirow{4}{*}{ Age groups } & & number & percentage \\
\hline \multirow{5}{*}{ Gender } & $<50$ & 20 & $40 \%$ \\
\cline { 2 - 4 } & $\geq 50$ & 30 & $60 \%$ \\
\hline \multirow{5}{*}{ Comorbidities } & Female & 49 & $98 \%$ \\
\cline { 2 - 4 } & Male & 1 & $2 \%$ \\
\hline \multirow{5}{*}{ Level of education } & Yes & 20 & $40 \%$ \\
\cline { 2 - 4 } & No & 30 & $60 \%$ \\
\cline { 2 - 4 } & Diabetes Mellitus (DM) & 9 & $18 \%$ \\
\cline { 2 - 4 } & Hypertension (HTN) & 18 & $36 \%$ \\
\cline { 2 - 4 } & High & 11 & $22 \%$ \\
\hline Stage-treatment plan & Uptohigh & 23 & $46 \%$ \\
\cline { 2 - 4 } & Illiterate & 16 & $32 \%$ \\
\cline { 2 - 4 } & Metastatic (palliative) & 17 & $34 \%$ \\
\hline
\end{tabular}

The questionnaire translated to Arabic then content validated by three oncology professors. The questionnaire then applied on ten patients for face validation. All questions and answers were understood by the patients except for question five and question six. In question five a choice "no worry" added and also in question six a choice "nothing" added. The modified final questionnaire then applied on forty patients. The responses to the survey collected. All of the patients want to continue their chemotherapy. Most of the patients fear suffering from cancer if treatment stopped. Also, most of the patients know that chemotherapy causes immunosuppression which makes them at higher risk of having complications from COVID-19. Table (2).

In this study, nearly half of patients (46\%) have good knowledge about COVID-19 regarding spread, symptoms and outcome. All of the patients want to continue their chemotherapy. Most of the patients have no history of domestic travelling (92\%) or contact with any one travelled abroad (96\%) in the past 30 days. Nearly half of our patients $(48 \%)$ have no worry about catching COVID-19. One third of the patients (32\%) were bothered about cancer progression, almost one third (28\%) were bothered about deferring chemotherapy and the other one third (28\%) nothing was bothering them. Most of the patients (72\%) knew that chemotherapy causes immunosuppression which increase the risk of complications in case of catching COVID-19. Most of the patients (90\%) fear suffering from cancer progression if treatment stopped. 
Tarek Hussien Kamel, et al.,

Table (2) responses to survey questions

\begin{tabular}{|c|c|c|}
\hline 1 & $\begin{array}{l}\text { Do } \quad \text { you } \\
\text { (spread/symptoms/outcome)? }\end{array}$ & $\begin{array}{l}\text { a)very much (23) } 46 \% \\
\text { b)moderate (8) } 16 \% \\
\text { c)minimal (19) } 38 \%\end{array}$ \\
\hline 2 & Do you want to continue or defer your chemotherapy? & $\begin{array}{l}\text { a)Continue (50) } 100 \% \\
\text { b)Defer (0) } \\
\text { c)Don't know (0) }\end{array}$ \\
\hline 3 & $\begin{array}{l}\text { Did you have any direct contact history in the past } 30 \text { days } \\
\text { with anyone who traveled abroad? }\end{array}$ & $\begin{array}{l}\text { a)Yes (2) } 4 \% \\
\text { b)No (48) } 96 \%\end{array}$ \\
\hline 4 & $\begin{array}{l}\text { Did you travel to another city inside the country in the past } \\
30 \text { days? }\end{array}$ & $\begin{array}{l}\text { a)Yes (4) } 8 \% \\
\text { b)No (46) } 92 \%\end{array}$ \\
\hline 5 & Are you worried about catching SARS-CoV-2? & $\begin{array}{l}\text { a)very much (7) } 14 \% \\
\text { b)moderate (9) } 18 \% \\
\text { c)minimal (10) } 20 \% \\
\text { d)no worry (24) } 48 \%\end{array}$ \\
\hline 6 & $\begin{array}{l}\text { Which is predominantly bothering you or your family } \\
\text { member now? }\end{array}$ & $\begin{array}{l}\text { a)Deferring chemotherapy (14) } 28 \% \\
\text { b)Visiting the hospital (3) } 6 \% \\
\text { c)Both A and B (3) } 6 \% \\
\text { d)cancer progression (16) } 32 \% \\
\text { e)nothing (14) } 28 \%\end{array}$ \\
\hline 7 & $\begin{array}{l}\text { Do you know that chemotherapy can lower your immunity } \\
\text { and increases the chance of increased suffering and/or death } \\
\text { as a result of COVID-19? }\end{array}$ & $\begin{array}{l}\text { a) Yes (36) } 72 \% \\
\text { b) No (14) } 28 \%\end{array}$ \\
\hline 8 & Which do you fear most at the moment? & $\begin{array}{l}\text { a)suffering from cancer if we stopped or } \\
\text { defer chemotherapy (45) } 90 \% \\
\text { b)getting infected and/or dying as a } \\
\text { result of SARS CoV-2 either in the } \\
\text { community or the hospital (5) } 10 \%\end{array}$ \\
\hline 9 & $\begin{array}{l}\text { What measures are you taking at home to prevent getting } \\
\text { SARS-CoV-2? }\end{array}$ & $\begin{array}{l}\text { a)wearing mask (19) } 38 \% \\
\text { b)frequent hand washing (30) } 60 \% \\
\text { c)hand sanitizer (35) } 70 \% \\
\text { d)social distancing (13) } 26 \% \\
\text { e)self-quarantine (3) } 6 \%\end{array}$ \\
\hline
\end{tabular}

Questions were correlated with age, comorbidities, level of education, aim of treatment and knowledge about immunosuppression.

In question one, knowledge about COVID-19 among breast cancer patients was significantly correlated with age $<50$ years old $(\mathrm{P}=0.0293)$. There was no significant correlation between knowledge about COVID-19 and level of education, aim of treatment or knowledge about immunosuppression. Table (3)

Table (3) correlation between Q1 (COVID know) and age group ( $<50 \mathrm{vs.} \geq 50$ )

\begin{tabular}{|l|l|l|}
\hline & Q1 (COVID_know) & \\
\hline Age group & Minimal/moderate & Very much \\
\hline$<50$ & $7(35 \%)$ & $13(65 \%)$ \\
\hline$\geq 50$ & $20(66.7 \%)$ & $10(33.3 \%)$ \\
\hline Chi-squared & 4.747 & \\
\hline Significance level & $\mathrm{P}=0.0293$ \\
\hline
\end{tabular}

In question five, worry about COVID-

19 among breast cancer patients in our study was significantly correlated with age $(\mathrm{P}=$

0.0232). One third of patients less than fifty years old had moderate worry about COVID-19 while in one third of patients 


\section{Knowledge, Attitude And Perception Of A Sample Of Breast Cancer Patients Towards Covid-19 Pandemic}

older than 50 years old their worry about COVID-19 was minimal. Almost 50\% of patients in both age groups there was no worry about COVID-19. There was no significant correlation between worry about COVID-19 and comorbidities, level of education, aim of treatment or knowledge about immunosuppression. (Table 4)

Table (4) correlation between Q5 (worry about COVID) and age group ( $<50$ vs. $\geq 50$ )

\begin{tabular}{|l|l|l|l|l|}
\hline \multicolumn{5}{|l|}{ Q5 (worry_COVID) } \\
\hline Age group & Very much & moderate & minimal & No worry \\
\hline$<50$ & $2(10 \%)$ & $7(35 \%)$ & $1(5 \%)$ & $10(50 \%)$ \\
\hline$\geq 50$ & $5(16.7 \%)$ & $2(6.7 \%)$ & $9(30 \%)$ & $14(64.7 \%)$ \\
\hline Chi-squared & 9.511 & & \\
\hline Significance level & $\mathrm{P}=0.0232$ & & \\
\hline
\end{tabular}

In question six, the predominant bother to the patient or his/her family members is strongly correlated with the level of education $(\mathrm{P}=0.0498)$. About two thirds of patients with high level of education (63.6\%) were more bothered about deferring chemotherapy. One third of patients with up to high education were bothered about cancer progression, while one third were not bothered about anything. More than one third of illiterate patients $(43.7 \%)$ were bothered about cancer progression, while one third of illiterate patient were not bothered about anything. Table (5)

Table (5) correlation between Q6 (bothering most) and education

\begin{tabular}{|l|l|l|l|l|l|}
\hline \multicolumn{5}{|l|}{ Q6 (bothering most) } \\
\hline Level of education & Defer chemo & Visit hospital & A \& B & $\begin{array}{l}\text { Cancer } \\
\text { progress }\end{array}$ & No worry \\
\hline high & $7(63.6 \%)$ & $0(0.0 \%)$ & $2(18.2 \%)$ & $1(9.1 \%)$ & $1(9.1 \%)$ \\
\hline uptohigh & $4(17.4 \%)$ & $2(8.7 \%)$ & $1(4.3 \%)$ & $8(34.8 \%)$ & $8(34.8 \%)$ \\
\hline illiterate & $3(18.8 \%)$ & $1(6.2 \%)$ & $0(0.0 \%)$ & $7(43.7 \%)$ & $5(31.2 \%)$ \\
\hline Chi-squared & 15.521 & & \\
\hline Significance level & $\mathrm{P}=0.0498$ & & \\
\hline
\end{tabular}

\section{DISCUSSION}

This study is to assess the knowledge, attitude and perception of breast cancer patients towards COVID-19 and their willingness about continuing their chemotherapy or not during the pandemic. This study consisted of 50 patients most of them were females as breast cancer is the most common cancer in females. (Dey et al 2010)

In our study, the amount of knowledge and information the patients have regarding COVID-19 (question one) is striking. Only $46 \%$ of the patients have good knowledge about COVID-19 and 36\% had minimal knowledge about the virus. Our population has a mixture of rural and urban patients, which may account for the even distribution of their perception of knowledge between well informed and moderately/minimally informed. Also In a study in Nigeria done on general population showed that almost one third had good knowledge about COVID-19.

\section{(Habib et al 2021)}

There is significant correlation between knowledge about COVID-19 and patients $<50$ years old $(\mathrm{P}=0.0293)$. This reflects that young patients are more aware and have more knowledge about COVID-19 more than old patients due to their contact with social media and news. There was no significant correlation between knowledge 
about COVID-19 and aim of treatment ( $\mathrm{P}=$ 0.0982), knowledge about immunesuppression $(\mathrm{P}=0.1944)$ and level of education $(\mathrm{P}=0.6641)$. On the contrary, in the study done in India (Ghosh $\mathbf{J}$ et al 2020) Knowledge about COVID-19 strongly correlated with curative intent of treatment $(\mathrm{P}=0.01)$, knowledge about immunesuppression $(\mathrm{P}=0.001)$ and higher level of education $(\mathrm{P}=0.003)$. There was no significant correlation with age.

All the patients $(100 \%)$ in this study wanted to continue their chemotherapy treatment. On the other hand, in India, only $68 \%$ of patients wanted to continue their chemotherapy. (Ghosh J et al 2020) This reflects that the patients are worried about cancer more than COVID-19.

$68 \%$ of the patients in this study had no/minimal worry about catching COVID19 which is against the results in India, that approximately $40 \%$ of patients had either moderate or minimal worry. (Ghosh J et al 2020) While in Nigeria, almost $63 \%$ of population in the study had marked fear of catching COVID-19. (Habib et al 2021) This reflects that patients' main concerns were cancer and receiving chemotherapy. This finding probably reflects the confidence in the precautions patients were taking to prevent infection because they were all undergoing chemotherapy, or may be due to their religious beliefs, so the patients did not have much fear. Patients' worry about catching COVID-19 was strongly correlated with their age $(\mathrm{P}=0.0232)$. One third of patients less than 50 years old had moderate fear about catching COVID-19, however one third of patients older than 50 years old had minimal worry about catching the virus. This reflects that due to the more knowledge the young patients had about COVID-19 compared to old patients, the more worry they had about catching it. On the other hand, in India, Worry about catching SARSCoV-2 strongly correlated with palliative intent of treatment $(\mathrm{P}=0.001)$ and higher knowledge about the immunosuppressive effects of chemotherapy $(\mathrm{P}=0.02)$. (Ghosh $J$ et al 2020). While in a study done in Milan, Italy among young people (Casanova et al 2020) approximately $71 \%$ of them had no/minimal fear from catching COVID-19. $60 \%$ of patients who were on chemotherapy had no/minimal fear of catching COVID-19 and 4\% were afraid very much about catching COVID-19.

Approximately one third of the patients (32\%) were bothered about cancer progression, $28 \%$ were bothered about deferring chemotherapy, $28 \%$ were not bothered about any of these. Few patients (6\%) were worried about visiting the hospital. Although they knew that our hospital is a tertiary hospital and many patients seek medical advice there, which may increase their risk for exposure to COVID-19, they came to the hospital on time to continue their treatment. This is with the results in India, one third were bothered about cancer progression if therapy was deferred and approximately two thirds of the patients were bothered about deferring chemotherapy, visiting hospitals, or both. (Ghosh $\mathbf{J}$ et al 2020) This reflects that patients were worried about cancer disease and continuing their treatment.

In this study, the predominant bother to the patient is strongly correlated with the level of education $(\mathrm{P}=0.0498)$. About two thirds of patients with high level of education $(63.6 \%)$ were more bothered about deferring chemotherapy. This reflects that patients with high level of education have good knowledge about the importance of treatment.

Knowledge about immunosuppression from chemotherapy among our patients was satisfying. Approximately two thirds of patients $(72 \%)$ actually knew that chemotherapy can cause immunesuppression.while in India, $50 \%$ of patients actually knew that chemotherapy can cause immunosuppression. (Ghosh J et al 2020) 


\section{Knowledge, Attitude And Perception Of A Sample Of Breast Cancer Patients Towards Covid-19 Pandemic}

This can reflect good pre-chemotherapy counseling or from their experience from receiving previous cycles and experiencing their side effects.

This study showed that $90 \%$ of patients were worried about cancer progression if their chemotherapy was stopped. The results were nearly the same in India, approximately $70 \%$ of patients were worried about cancer progression if their chemotherapy was stopped. (Ghosh $\mathbf{J}$ et al 2020)

For the ninth question, the majority of our patients were taking personal protective measures, including wearing masks (38\%), washing their hands $(60 \%)$, using hand sanitizer $(70 \%)$, and practicing social distancing (26\%). Approximately $6 \%$ of them were even practicing self-isolation, despite their COVID-19 status being unknown. Twelve patients (24\%) were taking three protective measures. Twenty patients $(40 \%)$ were taking two protective measures, twelve of them were wearing masks and had frequent hand washing. Sixteen patients $(32 \%)$ took one protective measure only, nine of them were using hand sanitizer. This reflects the lack of knowledge about the importance of wearing masks and practicing social distancing which are ones of the most important protective measures especially for them.

\section{Conclusion:}

This study shows that breast cancer patients are more worried about disease progression than COVID-19 and wish to continue chemotherapy during this pandemic.

\section{REFERENCES:}

1. Sahin, A.R. (2020). 2019 Novel Coronavirus (COVID-19) Outbreak: A Review of the Current Literature. Eurasian Journal of Medicine and Oncology.
2. Lai, C.C., Shih, T.P., Ko, W.C., Tang, H.J., and Hsueh, P.R. (2020). Severe acute respiratory syndrome coronavirus 2 (SARS$\mathrm{CoV}-2)$ and coronavirus disease-2019 (COVID-19): The epidemic and the challenges. International Journal of Antimicrobial Agents 55.

3. Li, X., Wang, W., Zhao, X., Zai, J., Zhao, Q., Li, Y., and Chaillon, A. (2020). Transmission dynamics and evolutionary history of 2019-nCoV. Journal of Medical Virology 92, 501-511.

4. WHO Director-General's opening remarks at the media briefing on COVID-19 - 11 March 2020. https://www.who.int/dg/speeches/detail/wh o-director-general-s-opening-remarks-atthe-mediabriefing-on-covid-19---11-march2020. Accessed March 12, 2020.

5. Coronavirus disease (COVID-19) Weekly Epidemiological Update,

https://www.who.int/docs/defaultsource/coronaviruse/situationreports/20200907-weekly-epi-update4.pdf?sfvrsn=f5f607ee_2

6. Li, Y., Qin, J.J., Wang, Z., Yu, Y., Wen, Y.Y., Chen, X.K., Liu, W.X., and Li, Y. (2020). [Surgical treatment for esophageal cancer during the outbreak of COVID-19]. Zhonghua Zhong Liu Za Zhi [Chinese Journal of Oncology] 42, 296-300.

7. Zhao, Z., Bai, H., Duan, J.C., and Wang, J. (2020). [Individualized treatment recommendations for lung cancer patients at different stages of treatment during the outbreak of 2019 novel coronavirus disease epidemic]. Zhonghua Zhong Liu Za Zhi [Chinese Journal of Oncology] 42, E007.

8. Wu, Z., and McGoogan, J.M. (2020). Characteristics of and Important Lessons from the Coronavirus Disease 2019 (COVID-19) Outbreak in China: Summary of a Report of 72314 Cases from the Chinese Center for Disease Control and Prevention. JAMA - Journal of the American Medical Association 323, 12391242.

9. Kim, Y.J., Lee, E.S., and Lee, Y.S. (2019). High mortality from viral pneumonia in 
patients with cancer. Infectious Diseases 51, 502-509.

10. Ménétrier-Caux, C., Ray-Coquard, I., Blay, J.Y., and Caux, C. (2019). Lymphopenia in Cancer Patients and its Effects on Response to Immunotherapy: An opportunity for combination with Cytokines? Journal for ImmunoTherapy of Cancer 7.

11. Han, H.J., Nwagwu, C., Anyim, O., Ekweremadu, C., and Kim, S. (2021). COVID-19 and cancer: From basic mechanisms to vaccine development using nanotechnology. International Immunopharmacology 90 .

12. Ghosh, J., Ganguly, S., Mondal, D., Pandey, P., Dabkara, D., and Biswas, B. (2020). Perspective of Oncology Patients During COVID-19 Pandemic: A Prospective Observational Study From India. JCO Global Oncology 844-851.
13. Dey, S., Soliman, A.S., Hablas, A., Seifeldein, I.A., Ismail, K., Ramadan, M., El-Hamzawy, H., Wilson, M.L., Banerjee, M., Boffetta, P., et al. (2010). Urban-rural differences in breast cancer incidence in Egypt (1999-2006). Breast 19, 417-423.

14. Casanova, M., Pagani Bagliacca, E., Silva, M., Patriarca, C., Veneroni, L., Clerici, C.A., Spreafico, F., Luksch, R., Terenziani, M., Meazza, C., et al. (2020). How young patients with cancer perceive the COVID19 (coronavirus) epidemic in Milan, Italy: Is there room for other fears? Pediatric Blood and Cancer 67.

15. Habib, M.A., Dayyab, F.M., Iliyasu, G., and Habib, A.G. (2021). Knowledge, attitude and practice survey of COVID19 pandemic in Northern Nigeria. PLoS ONE 16. 


\section{المعرفة والموقف والتأثر بين مرضى سرطان الثدي لوباء الكورونا

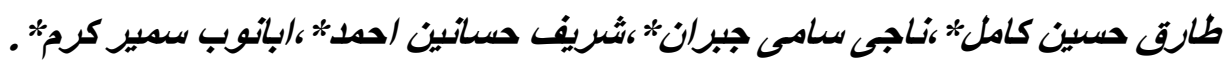

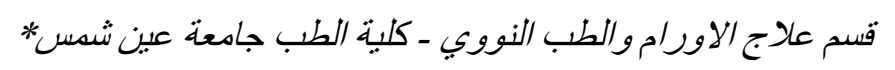

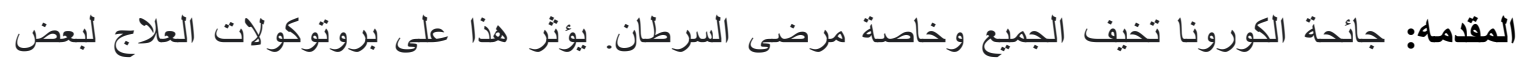

الههف من الاراسد: ترجمة الاستبيان إلى اللغة العربية والتحقق من صحته وتقيبيم معرفة المرضى وموققهم

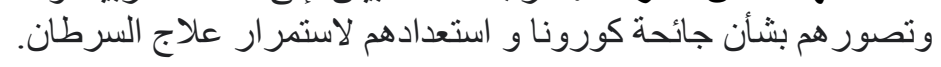

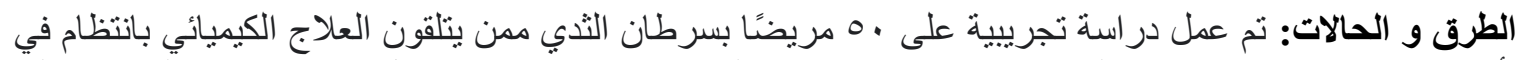

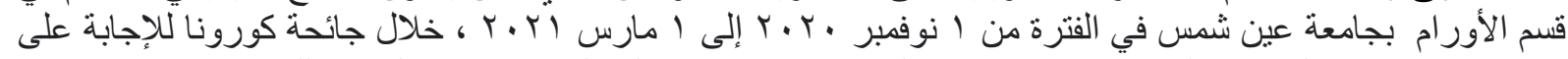

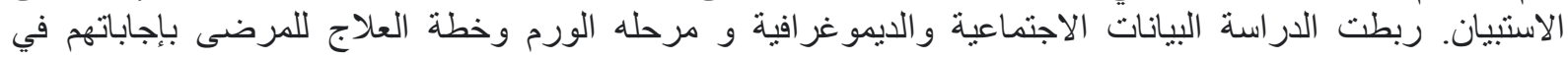

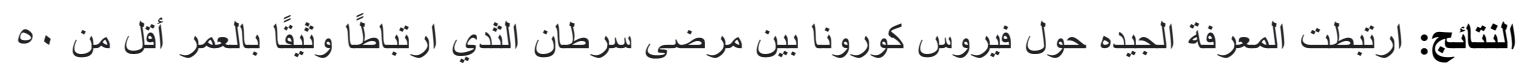

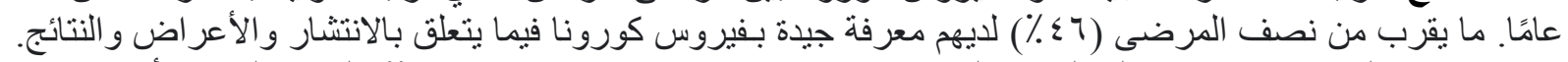

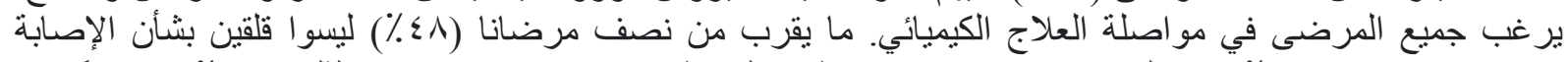

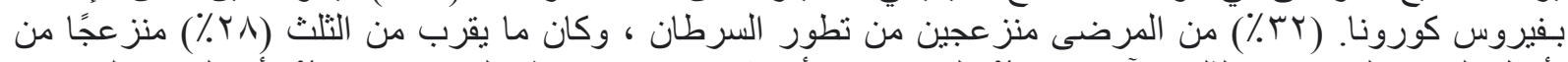

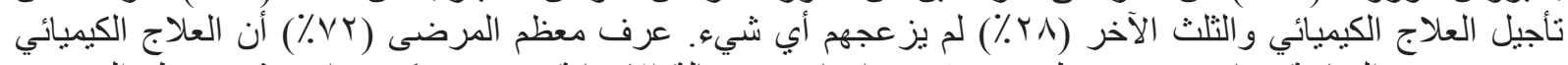

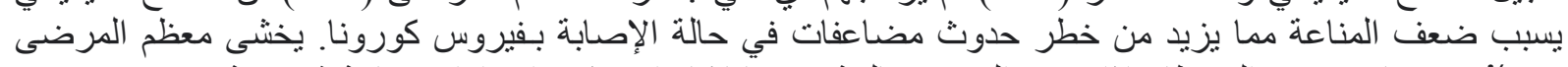

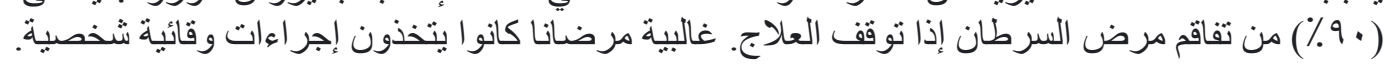

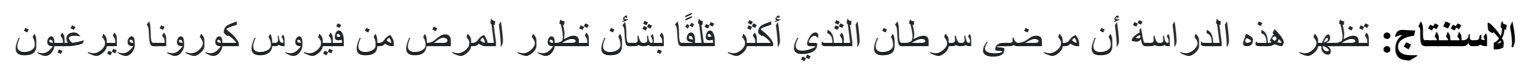

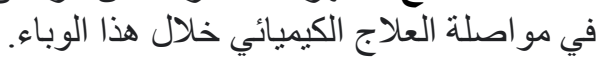

